\title{
Explaining differences between social groups: The impact of group identification on attribution*
}

\section{Olivier Klein ${ }^{1}$ and Laurent Licata}

Université Libre de Bruxelles

We present a study investigating the role of social identity processes in the explanation of intergroup differences. By transposing the fundamental attribution error hypothesis (Pettigrew, 1979), we predict that the explanation for differences favoring the out-group will be preferentially attributed to "external" factors (socio-structural factors or the action of a deviant sub-group). When differences favour the in-group, internal explanations (emphasizing cultural differences or differences in personality traits) are more likely to be selected. Moreover, if these differences are driven by identity protection, they should be highest among high identifiers. The study, which was conducted among Dutch-Speaking $(N=53)$ and French Speaking $(N=50)$ Belgian students, involved the explanation of four differences between the two linguistic groups. The data support the hypotheses in the case of two of these differences, French speakers being more likely to attribute differences favoring the in-group to internal causes than Dutch speakers, especially if they are strongly identified with their linguistic group. Results with respect to the two other differences are discussed within the framework of social identity theory.

Key words: Intergroup attribution, social identity, Belgium, ultimate attribution error, identification

A Flemish official interviewed by Van Dam (1997) as part of a large survey on the relations between linguistic groups in Belgium explained the unfavorable situation of Wallonia in comparison with Flanders in the following terms: "Wallonia suffers from a mentality which does not favor economic development. The prevailing culture is socialism. The socialist party sets the tone (...) Walloons tend to turn towards the government when problems arise" (p.

* We wish to thank Margarita Sanchez-Mazas, Rodrigo Brito and two anonymous referees for their valuable comments on a previous version of this article. We also express our gratitude to Frank Van Overwalle for his assistance in data collection. Part of this paper was written when the first author was a post-doctoral fellow of the Belgian Educational Foundation at the University of Minnesota. The two authors contributed equally to this research.
182, our translation). By contrast, a Walloon official explains the relative success of Flanders by its "geographical location (...), the ports in Antwerp and Zeebrugge. Thanks to these ports, a sizeable amount of economic activity passes through Flanders: they enable the region to communicate with the world." (p. 189). According to the first explanation, the economic disparities between the two regions are due to internal characteristics (their "culture", their "mentality"). The second explanation focuses on external factors (their geographical environment). Which factors may induce group members to favor one type of explanation at the expense of the other?

1 Supported by the Belgian National Fund for Scientific Research. 
The purpose of this article is to offer a partial answer to this question by focusing on the role of identification in the choice of an explanation. Since the pioneering studies by Taylor and Jaggi (1974), a large number of studies (see Deschamps, 1981; Deschamps \& Beauvois, 1994; Hewstone, 1989, 1990 for reviews) have revealed a tendency of people to use internal factors to explain desirable behavior of in-group members and external factors when the behavior is undesirable. The inverse generally obtains when the actor belongs to an out-group. This pattern reflects the "ultimate attribution error" (Pettigrew, 1979; Guimond, 1996). It is generally viewed as the expression of a form of in-group bias [as predicted, e.g., by social identity theory (Tajfel, 1981; Tajfel \& Turner, 1986)] contributing positively to self-esteem (Islam \& Hewstone, 1993).

The bulk of the work on this topic relies on the explanation of individual behaviors. By comparison, the few studies focusing on the explanation of collective phenomena are generally very descriptive (see, e.g., Furnham, 1988) and do not attempt to provide a link with attribution theory (for exceptions, see Guimond, 1998, 2000; Hegarty \& Pratto, 2001).

In the present study, we have attempted specifically to tackle a domain which lies at the intersection of research on intergroup attributions and what Hewstone (1990) calls "societal attributions" i.e., explanations of societal events and facts. Our aim is to clarify how members of two social groups explain societal phenomena that impact in contrasting ways on their respective groups. Although work on intergroup attributions often refers to motivations related to social identity maintenance or enhancement (Tajfel \& Turner, 1986), these studies generally do not include measures of identification (for an exception, see Guimond, 2000) or collective self-esteem (Luhtanen \& Crocker, 1992). Yet, if these interpretations are appropriate, the tendency to display in-group bias should depend on these variables. Indeed, people who strongly identify with their group are precisely those who should be most motivated to elicit positive differentiation for their group through favorable comparisons with relevant out-groups (Hinkle \& Brown, 1990). In line with this assumption, numerous studies have demonstrated the existence of a link between identification and a vast array of intergroup attitudes and behaviors (for an overview, see Ellemers, Spears, \& Doosje, 1999). If the ultimate attribution error (applied here to societal phenomena) fulfils a function of social identity protection, it should be most likely to arise among high identifiers. Indeed, in a study conducted with anglophone students in Canada (Guimond, 2000), the tendency to blame Francophones (rather than the "system") for their economically unfavorable situation increased as a function of linguistic identification. In addition, the fact that these explanations are in a large part determined by socialization processes (Guimond, 2000; Guimond, Begin \& Palmer, 1989; Guimond \& Palmer, 1990) confirms the role of group membership in the choice of an attribution.

The main purpose of the study presented in this paper was to determine whether identification indeed predicts the presence of the ultimate attribution error in the explanation of societal phenomena. Another goal of this study was to clarify the very concept of intergroup attributions around which it may be relevant to study this phenomenon. In this regard, it has an exploratory character. It aims at identifying more precise hypotheses with a view to future research. In view of this exploratory dimension, it was important to use open-ended answers in order to allow participants to organize their answers as freely as possible (Antaki, 1988). This we did.

The setting up of such a study naturally demands a selection of the phenomena to be explained. We therefore selected four societal phenomena having a different impact on the two main Belgian linguistic groups, French speakers (Walloons and most inhabitants of Brussels) and Dutch speakers (Flemings). These were: unemployment rate (higher in the French-speaking part of the country), percentage of senior citizens looked after by their family rather than in an old people's home (higher in the Frenchspeaking part), the electoral strength of far-right parties (higher in the Dutch-speaking part), and degree of bilingualism (higher in the Dutch-speaking part).

The participants' task was to explain the differential impact of the phenomena on the two linguistic groups. These phenomena can be grouped in two categories depending on whether they favor the French speakers or the Dutch speakers. The questions on bilingualism and unemployment favor Dutch speakers. Following the hypothesis derived from the relation between social identity theory and the ultimate attribution error, one should therefore observe the asymmetry traditionally found in individual attributions. Dutch speakers should be more likely to attribute their success to internal than to external factors whereas French speakers should be more likely to attribute the differences to external than internal factors. By contrast, differences in the popularity of far-right parties and in the care of senior citizens are to the advantage of French speakers. They respectively concern an undesirable phenomenon that is more prevalent in the Dutch-speaking part than in the French-speaking part and a desirable behavior, which is more frequent in the French-speaking part than in the Dutch-speaking part. One should therefore observe the opposite pattern of results.

When explanations are about the differential impact of societal phenomena on two groups, the distinction between internality and externality needs to be qualified, as 
it is not directly transposable. In the case of individual attributions, the concept of internality is based on an opposition between causes inherent in the actor and causes linked to the situation (Dubois, 1987). Obviously, the explanation of this impact of societal phenomena also invokes causal attribution. By definition, these causes must be other phenomena that differentially affect the two groups (Hegarty \& Pratto, 2001). We shall here consider four types of such causes:

\section{Internal Attributions}

"Stereotypical" explanations are based on the belief that certain individual psychological characteristics (personality traits, feelings, intentions, beliefs, etc.) are more frequent or more exaggerated among members of one group than in the other. The following answers to the open-ended question on the higher prevalence of far-right parties in Flanders were classified in this category: "The Walloons are lazy", "The feeling of threat from strangers is higher in Flanders"; "Flemings are racist".

"Culturalist" explanations concern beliefs, values, norms or behaviors attributed to the group taken as a whole rather than to its members individually. The following answers are part of this category: "because the French have a greater democratic tradition"; "because racism is more common in Flanders"; "because the Flemish mentality is selfish".

\section{External Attributions}

"Structural" explanations focus on factors lying outside the groups themselves (such as economic circumstances, the geographical environment or demography). A few examples: "Flanders is more urbanized"; "There are more immigrants in Flanders"; "More cultures are in contact in Wallonia".

The explanations can also focus on the activity, or the characteristics, of a deviant sub-group that may be the source of more global differences: The following answers were classified in this category: "the far-right parties are more powerful in Flanders", "Antwerp (in which one such party, the "Vlaams Blok", is popular) is in Flanders".

\section{Hypotheses}

Transposition of the ultimate attribution error to the explanation of intergroup differences should yield the following trends:

- When explaining differences favoring the in-group, internal explanations (cultural or stereotypical) will be used.

- When explaining differences favoring the out-group, external factors (structural or based on a sub-categorization) will be used.

- These trends should be stronger among high identifiers, as they are more motivated to protect their social identity (Tajfel \& Turner, 1986).

\section{Method}

\section{Participants and design}

The design was a 2 (Linguistic Group: French, Dutch) $\times 2$ (Identification: Low, High) $\times 2$ (Locus of explanation: Internal, External) and participants were undergraduate psychology students at the Universite Libre de Bruxelles (French speakers, $\mathrm{n}=50$ ) and at the Vrije Universiteit Brussel (Dutch-speakers, $\mathrm{n}=53$ ). Approximately $80 \%$ of participants in both samples were women.

\section{Procedure}

The study was presented in a questionnaire distributed at the end of a class. Participation was optional. The questionnaire was administered in the participants' native language. In order to ensure that the audience would be perceived as belonging to the in-group in all conditions (cf. Klein \& Azzi, 2001; Klein, Azzi, Brito \& Berckmans, 2000; Klein \& Licata, submitted, for audience effects), the authors of the study were presented as members of universities that were either Dutch- or French-speaking. The study was described as part of a larger survey on various social problems encountered in French-speaking Belgium (for French-speaking participants) or in Flanders (for Dutch-speaking participants):

"The GESPI is a research group studying social and political problems. It includes researchers at the major French-speaking (Dutch-speaking) universities (the names of the universities followed: either ULB, UCL, UMH, ULg for French speakers or RUG, KUL, UIA, VUB for Dutch speakers). The GESPI is presently conducting a large survey on the explanation of political, social and economic facts concerning French-speaking (Dutch-speaking) Belgium.” 
Participants were invited to offer explanations for a variety of statements describing differences between the Dutch- and the French-speaking parts of the country. These statements were presented in a random order. Participants were asked to provide the most plausible explanation, even if they thought they did not possess all the necessary information:

"Below, you will find a series of statements describing differences between Belgian regions. For each statement, please suggest an explanatory hypothesis. Write concisely the hypothesis that seems most plausible even if all the necessary information is not available."

No time limit was fixed. After having provided these explanations, participants were asked to report their level of identification by expressing the degree to which the statement "I feel Flemish" (vs. French-speaking Belgian) applied to themselves $(1=$ not at all, $9=$ very much). The apparent discrepancy between the types of identifications chosen here (regional vs. linguistic) is due to the Belgian socio-historical context. The Flemish identity is defined in territorial and cultural terms, as a form of ethnicity (Van Dam, 1997; Witte, 1999). In spite of its role in differentiation from the Francophones, and in the emancipation of Flanders, the Flemish identity is not defined solely by its language. French speakers include both Walloons and inhabitants of Brussels who share a similar linguistic identity but this identity, shared with other countries, is not defined in relation to a culture or a territory specific to Belgium. In this case, the language thus circumscribes a common group membership (this distinction is present in the names of the political entities representing these groups: "Flemish Community" vs. "French Speaking Community of Belgium").

Once the questionnaires were collected, participants were debriefed and thanked.

\section{Coding}

Answers were relatively short (between 10 and 15 words in average). Each answer was coded in one of the four categories described above by two independent judges $(\kappa>$ .78 for each question with disagreements being resolved through discussion). The answers provided by Dutchspeaking participants were translated into French before being coded. As stated above, "Stereotypical" and "Culturalist" explanations were considered as internal whereas "Structural" explanations and explanations relying on a sub-categorization were considered as external.

The analyses were performed on the frequencies of internal and external explanations among Dutch- and French-speaking participants respectively. Additionally, we considered level of identification through a median split $($ median $=6)$. On average, the two groups did not differ reliably in their levels of identification, $(M s=5.53$ and 6.08 respectively for the French- and Dutch speakers, $t(101)=1.09, p=.13)$.

\section{Results}

A hierarchical log-linear analysis (for an introduction, see Klein \& Azzi, 1999) was used in order to examine the dependencies between identification, group membership and the locus of attribution. The default model included identification, group, locus and the dependence between identification and group.

\section{Difference in the rate of unemployment ${ }^{2}$}

7 participants ( 3 French speakers and 4 Dutch speakers) did not answer this question. The log-linear analysis did not reveal any effect of the independent variables on the locus of attribution (for the default model, $G^{2}(3)=1.33$, $p=.72$ ). The answers were generally external, and more specifically structural (85\%). Differences in the industrial infrastructure (28\%) of the two regions were mentioned frequently: Wallonia's industry is more decayed. Other explanations refer to the global economic context (26\%) which is more favorable to Flanders because the Walloon economy mainly involves declining industrial sectors (steel works, mining, etc.)

\section{Difference in the rate of bilingualism ${ }^{3}$}

2 participants (1 Dutch speaker and 1 French speaker) failed to answer this question. Again, the log-linear analysis did not reveal any effect of the independent variables, $\left(G^{2}(3)=1.42, p=.70\right)$. Answers were generally external and structural $(77 \%)$. Some of the explanations referred to differences in the educational systems (32\%): the educational system in Flanders was viewed as more adapted to language teaching. In addition, the wider international reach of French was frequently mentioned (29\%): it would be more useful for Dutch speakers to learn French than for French-speakers to learn Dutch.

2 Why is the percentage of unemployed people higher in Wallonia than in Flanders (Wallonia: 17.8; Flanders: 9.3\%)?

3 Why are there more bilinguals among the Dutch speakers than among the French speakers?

Swiss J Psychol 60 (4), 2001, ㄷ Verlag Hans Huber, Bern 


\section{Difference in the care of senior citizens ${ }^{4}$}

9 participants (2 Dutch speakers, 7 French speakers) did not answer this question. The log-linear analysis reveals a reliable dependence between group and locus, $G^{2}(1)=$ $4.95, p=.026$ : French speakers were more likely to attribute the differences to internal causes than Dutch speakers (see Table 1). This effect is not significantly dependent on the level of identification, $G^{2}(1)=1.87$, $p=.17$. However, an inspection of the contingency table (see Table 1) shows that, among high identifiers, the proportion of internal explanations differs as a function of group membership. French speakers are more likely to use internal explanations than Dutch speakers, as testified by the presence of a dependence between group and locus among high identifiers, $G^{2}(1)=6.73 ; p=.009$. By contrast, and regardless of their group membership, low identifiers are equally likely to use internal and external explanations, $G^{2}(1)=.089 ; p=.76$. Hence high identifiers were almost entirely responsible for the effect of group upon locus of explanation.

Regardless of the level of identification and group membership, the vast majority of internal explanations $(95 \%)$ were cultural (e.g., family values viewed as more important in Wallonia) whereas external explanations were almost exclusively structural (96\%: the prosperity of Flanders, the level of unemployment in Wallonia, differences in the quality of old people's homes). Most explanations (the $67 \%$ of explanations that were not directly comparative) focused on Wallonia.

\section{Difference in the political strength of far-right political parties ${ }^{5}$}

6 participants (2 French speakers, 4 Dutch speakers) did not answer this question. The analysis revealed a dependence between group and locus $\left(G^{2}(1)=4.76 ; p=.029\right)$ : French speakers were more likely than Dutch speakers to explain the differences by internal factors. Nevertheless, this effect depended upon the level of identification, $G^{2}(1)=12.79 ; p=<.001$. Among French speakers, only high identifiers offered more internal than external explanations. Among Dutch speakers, the reverse pattern was present (see Table 2). Indeed, among high identifiers, the independence of locus and group was not present $\left(G^{2}(1)\right.$ $=15.22, p<.001)$ but it was among low identifiers $\left(G^{2}(1)\right.$ $=2.23, p=.127$ ). $64 \%$ of highly identified French speakers explained the difference by incriminating stereotypical traits attributed individually to Flemings: they were described as racist, individualistic or intolerant. 9\% referred to cultural values prevalent in Flanders such as nationalism. The majority of highly identified Dutch speakers mentioned external (70\%) and mainly structural causes (53\%): a higher level of immigration into Flanders, a greater familiarity with the French than with the Dutch language among immigrants. $13 \%$ used sub-categorizations. These participants attributed the difference to the activity of the Vlaams Blok, a far-right party. However, a substantial proportion of high identifiers $(26 \%)$ referred to internal causes. These explanations are somewhat different from those proposed by the French speakers: only one referred to the "selfishness" of Flemings. The other explanations mentioned a feeling of threat experienced by Dutch speakers ( 2 answers), an attitude of protest towards politics (2 answers) or towards the job market (1 answer). The presence of important differences between explanations classified within the same category ("stereotypical") points to the need to analyze explanations without being bound by a rigid thematic categorization.

Weakly identified French speakers mentioned as many internal as external causes. By contrast, weakly identified Dutch speakers were more likely to mention internal than external causes. In this case, the internal explanations were very similar to those proposed by the French speakers (intolerance, racism, and nationalism). Contrary to the pre-

4 Why do more families take care of older people who have lost their autonomy in Wallonia than in Flanders?

5 Why is the percentage of votes for far-right parties higher among Flemish than French-speaking voters (Vlaams Blok: 13.3\%; Front National: 5.7\%)?

Table 1: Frequency of locus of attribution for the difference in the care of senior citizens as a function of linguistic group and identification

\begin{tabular}{|c|c|c|c|c|c|c|}
\hline \multirow[t]{3}{*}{ Identification } & \multicolumn{3}{|c|}{ Low } & \multicolumn{3}{|c|}{ High } \\
\hline & \multicolumn{3}{|c|}{ Attribution } & \multicolumn{3}{|c|}{ Attribution } \\
\hline & Internal & External & Total & Internal & External & Total \\
\hline \multicolumn{7}{|l|}{ Group: } \\
\hline French speakers & 8 & 8 & 16 & 18 & 9 & 27 \\
\hline Dutch speakers & 9 & 11 & 20 & 9 & 22 & 31 \\
\hline Total & 17 & 19 & 36 & 27 & 31 & 58 \\
\hline
\end{tabular}

Note: Each subject's answer was coded as "internal" or "external". There is only one observation per participant. 
vious question, the target of explanations was generally Flanders (75\% of explanations did not involve direct comparisons).

\section{Discussion}

Among the four questions considered here, two elicited divergent explanations on the part of the two linguistic groups: the question concerning the care of older citizens and the question on the political weight of far right parties. In both instances, as in Guimond's study (2000), these divergences were moderated by the level of identification with the linguistic group: high identifiers differed more as a function of group membership than did low identifiers. Considering that these two phenomena favor French speakers, these differences are in line with the ultimate attribution error: indeed French speakers who were highly identified relied more frequently on internal explanations whereas highly identified Dutch speakers preferred external explanations. Answers to the two other questions (about unemployment and bilingualism) did not vary as a function of group membership, both groups using similar explanations (usually external).

The prevalence of external explanations for differences in unemployment may seem surprising, especially among Dutch speakers. Research on lay explanations for unemployment conducted in industrialized countries reveals a sizeable proportion of internal explanations generally based on a stigmatization of the unemployed (Furnham \& Stacey, 1991; Heaven, 1989; Murray \& Millar, 1992; Ward, 1991). Moreover, a stereotype shared in Flanders (Nuttin, 1976) describes French speakers as more lazy and idle than their work-oriented neighbors. The availability of this representation should contribute to the use of internal explanations. Its absence may be due in part to socialization: students in the social sciences often tend to prefer external explanations for social phenomena (Guimond et al. 1989; Guimond \& Palmer, 1996). The role of socialization may also explain the absence of forms of explanations found in related research (Apostle, Glock, Piazza \& Suelzle, 1983), such as "supernatural" explanations (which involve the action of divine forces) or "genetic" explanations. The anticlerical and positivist values of the universities in which this study was conducted probably explains the absence of the former type of explanations and the predilection for external explanations among social science students the absence of the latter type of explanations (which are also stigmatized because of their association with biological racism).

However, the absence of asymmetry on two questions still begs explanation. Consideration of two factors may help to explain this unexpected result: the relative status of the two groups and the nature of the threat induced by the questions.

Before examining these factors in more detail, it is important to note that the expected pattern was found on the differences favoring French speakers. In both instances, French speakers favoured internal attributions. By a massive majority they offered external explanations for the two other differences, which favoured Dutch speakers. Hence, the answers provided by the French speakers conform to the hypotheses in the four cases. The cause of the unexpected results on the questions concerning differences in bilingualism and unemployment are to be found in Dutch speakers' explanations ${ }^{6}$.

Taking into account the relative status of the two groups may prove useful for interpreting this result. At the time

6 Note that it is quite difficult to explain the absence of results among Flemings by the different content of the identification item (linguistic amongst French speakers, regional amongst Dutch speakers). This would demand an assumption that a linguistic identity (in this case, the French-speaking identity) is more likely to influence intergroup perceptions and behaviors than a regional identity (here, the Flemish identity). By contrast, the Flemish identity is generally viewed as better organized and defined than the "Belgian French-speaking" identity, which is mainly defined in opposition to the former (Maddens, Beerten \& Billiet, 1998).

Table 2: Frequency of locus of attribution for the difference in the political strength of far-right political parties as a function of linguistic group and identification

\begin{tabular}{|c|c|c|c|c|c|c|}
\hline \multirow[t]{3}{*}{ Identification } & \multicolumn{3}{|c|}{ Low } & \multicolumn{3}{|c|}{ High } \\
\hline & \multicolumn{3}{|c|}{ Attribution } & \multicolumn{3}{|c|}{ Attribution } \\
\hline & Internal & External & Total & Internal & External & Total \\
\hline \multicolumn{7}{|l|}{ Group: } \\
\hline French speakers & 8 & 9 & 17 & 24 & 7 & 31 \\
\hline Dutch speakers & 13 & 5 & 18 & 9 & 22 & 31 \\
\hline Total & 21 & 14 & 35 & 33 & 29 & 62 \\
\hline
\end{tabular}

Note: Differences in sample size between the two tables are due to missing values. 
of this study, the Flemish population is a majority in Belgium and Flanders globally has a higher economic and political status (Maddens, Beerten \& Billiet, 1998). Other studies conducted with similar populations have shown that these differences in numerical size and status are the object of a consensual representation (Licata, 2001). The present results show that highly identified members of a disadvantaged minority group manifest ingroup enhancement (on the question concerning the care of senior citizens) or out-group derogation (on the question concerning the political strength of far right parties). On the other hand, when the differences favour the advantaged majority group, its members use external attributions. In other words, they do not take advantage of the opportunity to flatter their own group and to enhance their social identity. This may be due to the security of their social identity (Tajfel \& Turner, 1986): members of an advantaged group do not necessarily need to maintain a (globally positive) social identity when comparison with the lower status is perceived as stable and legitimate (Ellemers \& van Knippenberg, 1997; Ellemers, Wilke \& Van Knippenberg, 1993; Spears, Jetten \& Doosje, 2001).

Moreover, the content of the differences is probably important as it affects the nature of the threat bearing on social identity and the choice of strategies for coping with this threat. In this respect, Branscombe, Ellemers, Spears and Doosje (1999) make a distinction between threats to the value of a group as a function of whether they concern competence or morality. In the domain of competence (which defines the status difference between Flanders and Wallonia), "reality constraints" limit the credibility of attempts at in-group favoritism on the part of members of the lower status group: the descriptive or evaluative differences between the two groups are consensual and thereby define social reality (Ellemers \& Van Knippenberg, 1997; Ellemers et al., 1993). By contrast, in the domain of morality, one may expect defensive reactions on the part of high identifiers, even if their group is advantaged. According to Branscombe et al. (1999), low identifiers tend to accept moral accusations of their group. In the present instance, the questions that revealed divergent modes of explanations by members of the two groups (the care of senior citizen and the political strength of the far-right) have a moral character while the two other questions (bilingualism and unemployment) are more related to issues of competence. Moreover, the pattern of results for the "moral" differences conforms to the predictions made by Branscombe et al. (1999): participants who were highly identified with the advantaged group adopted defensive strategies (external attributions) when their group was threatened whereas weakly identified participants tended to accept accusations bearing on their group by using internal attributions (in the case of the question on the far-right parties).

The use of this strategy demands to be considered in the context of the immediate history of Belgium. When some Flemish representatives use the economic success of their region as a tool to obtain political advantage [for example, to press for greater autonomy (Mabille, 1993)], an affirmation of the "morality" of the in-group may be an effective counter-strategy on the part of French speakers. This morality stands in opposition to the "selfishness", "racism", and "nationalism" attributed to the Flemings (Provost, 1998) and disqualifies their separatist inclinations, which are viewed as an expression of these "vices". A similar strategy was also observed in the unprecedented civic movement that emerged (especially in Wallonia) after the Dutroux affair. In response to a threatened national identity, this movement aimed at restoring the morality of institutions and at affirming the virtue of the people in contrast to its political leaders (Licata \& Klein, 2000). Hence, our results should be integrated into a wider analysis of the political uses of the moral and of morality.

In the present study, the desirability of the difference, the status of the groups involved and the type of threat induced by the questions were not independent; differences favorable to the majority group concerned competence while differences favorable to the minority group concerned morality. In order to evaluate the relative influences of each of these factors, future studies will need to manipulate these three variables independently.

\section{Conclusion}

This study seems to confirm that it is productive to extend the work on inter-group attributions, which has hitherto focused almost exclusively on interpersonal behavior, to explanations of societal phenomena exerting a different impact on two social groups. The ultimate attribution error (Pettigrew, 1979) seems likely to appear when differences involving large social groups have to be explained. Moreover, this study demonstrated the significance of subjective identification in this kind of attribution. Finally, these results open up new avenues for research. On the basis of the analysis proposed here, one may predict that the form of ultimate attribution error studied here is more likely to be present among highly identified individuals, among members of a disadvantaged group, and when the difference involves a moral dimension. 


\section{References}

Antaki, C. (1988). Analyzing everyday explanations. London: Sage.

Apostle, R. A., Glock, C.Y., Piazza, T. \& Suelzle, M. (1983). The Anatomy of Racial Attitudes. Los Angeles, CA: University of California Press.

Branscombe, N. R., Ellemers, N., Spears, R. \& Doosje, B. (1999). The context and content of social identity threat. In N. Ellemers \& R. Spears (Eds.), Social identity: Context, commitment, content. (pp. 35-58). Oxford, England: Blackwell Science Ltd.

Deschamps, J. C. (1981). Social Attribution. In J. Jaspars, F. Fincham \& M. Hewstone (Eds.), Attribution theory and research: conceptual, developmental and social dimensions (pp. 223-240). London: Sage.

Deschamps, J.-C. \& Beauvois, J.-L. (1994). Attributions intergroupes [Intergroup attributions]. In R.Y. Bourhis \& J.-P. Leyens (Eds.), Stéréotypes, discrimination et relations intergroupes (pp. 97-126). Liège, Belgium: Mardaga.

Dubois, N. (1987). La psychologie du contrôle: les croyances internes et externes [The psychology of control: internal and external beliefs]. Grenoble: Presses Universitaires de Grenoble.

Ellemers, N., Spears, R. \& Doosje, B. (1999). Social Identity. Oxford, UK: Blackwell.

Ellemers, N. \& Van Knippenberg, A. (1997). Stereotyping in social context. In R. Spears \& P. J. Oakes (Eds.), The social psychology of stereotyping and group life. (pp. 208-235). Oxford, England UK: Blackwell Publishers, Inc.

Ellemers, N., Wilke, H. \& Van Knippenberg, A. (1993). Effects of the legitimacy of low group or individual status on individual and collective status-enhancement strategies. Journal of Personality \& Social Psychology, 64, 766-778.

Furnham, A. (1988). Lay theories: Everyday understanding of problems in the social sciences. Oxford, UK: Pergamon Press, Inc.

Furnham, A. \& Stacey, B. (1991). Young people's understanding of society. London, England UK: Routledge.

Guimond, S. (1996). L'erreur ultime d'attribution [The ultimate attribution error]. In J. C. Deschamps \& J. L. Beauvois (Eds.), La psychologie sociale Tome 2: Des attitudes aux attributions - sur la construction de la réalité sociale (Vol. 2, pp. 255-258). Grenoble: Presses Unversitaires de Grenoble.

Guimond, S. (1998). L'enseignement supérieur et la diffusion des croyances concernant la cause des inégalités intergroupes. In J.-L. Beauvois, R.-V. Joule \& J.-M. Monteil (Eds.). Perspectives cognitives et conduites sociales, VI (pp. 185-207). Lausanne: Delachaux et Niestlé.

Guimond, S. (2000). Group Socialization and Prejudice: The Social Transmission of Intergroup Attitudes and Beliefs. European Journal of Social Psychology, 30, 335-354.

Guimond, S., Bégin, G. \& Palmer, D.L. (1989). Education and causal attributions: the development of "person-blame" and "system-blame" ideology. Social Psychology Quarterly, 52, 126-140.
Guimond, S. \& Palmer, D. L. (1990). Type of academic training and causal attributions for social problems. European Journal of Social Psychology, 20, 61-75.

Guimond, S. \& Palmer, D.L. (1996). The political socialization of commerce and social science students: epistemic authority and attitude change. Journal of Applied Social Psychology, 26, 1985-2013.

Heaven, P. C. (1989). Lay attributions of unemployment: Data from an Australian community sample. Australian Psychologist, 24, 239-248.

Hegarty, P. \& Pratto, F. (2001). The effects of social category norms and stereotypes on explanations for intergroup differences. Journal of Personality \& Social Psychology, 80, 723-735.

Hewstone, M. (1989). Causal attribution: From cognitive processes to collective beliefs. London: Basil Blackwell.

Hewstone, M. (1990). The "ultimate attribution error"? A review of the literature on intergroup causal attribution. European Journal of Social Psychology, 20, 311-335.

Hinkle, S. \& Brown, R. (1990). Intergroup comparisons and social identity: Some links and lacunae. In D. Abrams \& M. Hogg (Eds.), Social identity theory: Constructive and critical advances (pp. 48-70). Hemel Hempstead, UK: Harvester-Wheatsheaf.

Islam, M. R. \& Hewstone, M. (1993). Intergroup attributions and affective consequences in majority and minority groups. Journal of Personality \& Social Psychology, 64, 936-950.

Klein, O. \& Azzi, A.E. (1999). Log-linear analysis in social psychology: An introduction [Log linear analysis in social psychology: an introduction]. Cahiers Internationaux de Psychologie Sociale, 42, 102-124.

Klein, O. \& Azzi, A.E. (2001). The strategic confirmation of meta-stereotypes: How group members attempt to tailor an out-group's representation of themselves. British Journal of Social Psychology, 40, 279-294.

Klein, O., Azzi, A.E., Brito, R. \& Berckmans, S. (2000). Nationalism and the strategic expression of identity. In T. Postmes, R. Spears, M. Lea, \& S. D. Reicher (Eds.). SIDE issues centre stage: Recent developments in studies of deindividuation in groups (pp. 131-142). Amsterdam, the Netherlands: Royal Netherlands Academy of Arts and Sciences.

Klein, O. \& Licata L. (submitted). When stereotypes serve social change: the speeches of Patrice Lumumba during the congolese decolonization.

Licata, L. (2001). Identités représentées et représentations identitaires: l'effet des contextes comparatif et sociopolitique sur la signification psychologique des identités géopolitiques [Represented identities and 'identitarian' representations: the impact of the comparative and social psychological context on the psychological meaning of geopolitical identities]. Unpublished doctoral dissertation, Université Libre de Bruxelles, Belgium.

Licata, L. \& Klein. (2000). Situation de crise, explications profanes et citoyennete: l'affaire Dutroux [Crisis situation, lay explanations and citizenship: the Dutroux affair]. Cahiers Internationaux de Psychologie Sociale, 47-48, 155-174. 
Luhtanen, R. \& Crocker, J. (1992). A collective self-esteem scale: Self-evaluation of one's social identity. Personality \& Social Psychology Bulletin. 18, 302-318.

Mabille, X. (1993). Histoire Politique de la Belgique de 1830 à nos jours [Political History of Belgium from 1830 to the present]. Brussels, Belgium: Centre de Recherche et d'Histoire Socio-Politique.

Maddens, B., Beerten, R. \& Billiet, J. (1998). The national consciousness of the Flemings and Walloons. An empirical investigation. In K. Deprez (Ed.), Nationalism in Belgium (pp. 199-208). London: Macmillan.

Murray, M. \& Millar, R. (1992). Lay explanations of and solutions to unemployment in Northern Ireland. Work \& Stress, 6, 367-378.

Nuttin, J. (1976). Stereotypes of Flemish and Walloon ethnic groups in Belgium. Mededelingen van de Koninklijke Academie voor Wetenschappen, 38, 3-86.

Pettigrew, T.F. (1979). The ultimate attribution error: Extending Allport's cognitive analysis of prejudice. Personality \& Social Psychology Bulletin, 5, 461-476.

Provost, V. (1998). L'effet de la nature des représentations stéréotypiques sur la tendance à adopter un comportement à caractère nationaliste: Le cas des Flamands et des Wallons [the impact of the nature of stereotypical representations on nationalist behavior: the case of Flemings and Walloons]. Unpublished senior essay: Université Libre de Bruxelles, Belgium.

Spears, R., Jetten, J. \& Doosje, B. (2001). The (il)legitimacy of ingroup bias: from social reality to social resistance. In J.T. Jost \& B. Major (Eds.), The psychology of legitimacy. Cambridge, UK: Cambridge University Press.
Tajfel, H. (1981). Human Groups and Social categories. Cambridge: Cambridge Unversity Press.

Tajfel, H. \& Turner, J.C. (1986). The social identity theory of intergroup behavior. In S. Worchel \& W. G. Austin (Eds.), The psychology of intergroup relations (pp. 7-24). Chicago: Nelson-Hall.

Taylor, D. M. \& Jaggi, V. (1974). Ethnocentrism and causal attribution within a south Asian context. Journal of Social Psychology, 5, 162-174.

Van Dam, D. (1997). Flandre, Wallonie: le rêve brisé. Quelles identités culturelles et politiques en Flandre et en Wallonie? [Flanders, Wallonia: the broken dream. Louvain-La Neuve, Belgique: Quorum.

Ward, E. A. (1991). An international comparison and psychometric analysis of explanations for unemployment. Psychological Reports, 68, 315-321.

Witte, E. (1999). Langue et politique: la situation en Belgique dans une perspective historique [Language and politics: the Belgian situation in a historical perspective]. Brussels: VUB Press.

\section{Olivier Klein}

Service de Psychologie Sociale CP 122

Université Libre de Bruxelles

50 av. F. Roosevelt

B-1050 Bruxelles

E-mail: oklein@ulb.ac.be 